\title{
EFFECTIVENESS OF MUSCLE ENERGY TECHNIQUE TO INCREASE HAMSTRING MUSCLE FLEXIBILITY IN ADOLESCENTS
}

\author{
Afif Ghufroni, Jasmine Kartiko Pertiwi \\ Physiotherapy Study Program, School of Health Polytechnics, Surakarta, Indonesia
}

\begin{abstract}
Background: Shortening of the hamstring muscles results in pain, limited range of motion, postural instability, and abnormal gait, which effect on daily activities. Muscle energy technique provides a solution to shortening the hamstring muscles by improving muscle flexibility. This study aimed to examine the effectiveness of muscle energy technique in increasing hamstring muscle flexibility in adolescents.

Subjects and Method: This was a quasi-experiment pretest-posttest without a control group conducted at No. 1 High School Jogonalan, Klaten, Central Java in April 2018. A total of 30 students was selected with purposive sampling method in which one student dropped out. The dependent variable was flexibility of hamstring muscle. The independent variable was muscle energy technique training. The flexibility of hamstring muscle was measured by back saver sit and reach test. Data were analyzed by Wilcoxon test.

Results: Flexibility of hamstring muscle was higher after muscle energy technique $(\mathrm{Mean}=39.92 ; \mathrm{SD}=4.24)$ than before $($ Mean=30.14; $\mathrm{SD}=3.59)$, and it was statistically significant $(\mathrm{p}<0.001)$.

Conclusion: Muscle energy technique increases flexibility of hamstring muscle. Muscle exercise technique can be used to improve hamstring muscle flexibility.
\end{abstract}

Keywords: muscle energy technique, flexibility, hamstring muscle, adolescents

\section{Correspondence:}

Afif Ghufroni. Physiotherapy Study Program, School of Health Polytechnics, Surakarta, Indonesia. Email: apip.physio@gmail.com. Mobile: +6285725000769.

The $7^{\text {th }}$ International Conference on Public Health

Solo, Indonesia, November 18-19, 2020 | 140 https://doi.org/10.26911/the7thicph.02.29 